American Journal of Infectious Diseases 1 (2): 107-110, 2005

ISSN 1553-6203

(c) 2006 Science Publications

\title{
Review of Pasteurella Multocida Infections over a Twelve-Year Period in a Tertiary Care Hospital
}

\author{
Athanasia Christidou, Sofia Maraki, Zoe Gitti and Yiannis Tselentis \\ Department of Clinical Bacteriology, Parasitology, Zoonoses and Geographical Medicine \\ University Hospital of Heraklion, P.O. Box 1352, Heraklion 71 110, Crete, Greece
}

\begin{abstract}
The aim of this study was to present the epidemiological, clinical and microbiological data, as well as the management and the outcome of 13 patients with documented Pasteurella multocida infections, diagnosed in the University hospital of Crete, Greece, between 1993 and 2004. Most patients $(62 \%)$ were $>70$ years of age. Respiratory tract infections were most commonly encountered $(61.5 \%)$, followed by soft-tissue infections $(30.8 \%)$ and septicemia $(7.7 \%)$. Underlying diseases included malignancies, bullous pemphigoid, mitral valve stenosis, coronary disease, chronic obstructive pulmonary disease and intracranial hemorrhage. Antibiotic sensitivity testing showed that all $P$. multocida isolates were susceptible to beta-lactams, quinolones, chloramphenicol, tetracycline and trimethoprim/sulfamethoxazole. Antibiotics were administered to all 13 patients and a clinical response was observed in $77 \%$ of them. The overall mortality rate was $23 \%$ (3/13) but only $15.4 \%$ $(2 / 13)$ died from the infection. Although rare, $P$. multocida infections should be suspected in patients reporting animal exposure, particularly in those with chronic underlying diseases.
\end{abstract}

Key words: Pasteurella multocida, infections, zoonoses, Greece

\section{INTRODUCTION}

Pasteurella multocida, a Gram-negative coccobacillus, is a member of the normal flora of the upper respiratory and gastrointestinal tract of many domestic and wild animals ${ }^{[1]}$. Human infections due to $P$. multocida are strongly associated with animal exposure and usually involve soft-tissue sites after animal bites or scratches ${ }^{[2,3]}$. Respiratory tract infections and less frequently septicemia, endocarditis, meningitis, peritonitis, or other unusual types of infection due to this organism have also been described ${ }^{[4-8]}$. In this study we present 13 cases of $P$. multocida infection diagnosed in our hospital during a 12-year period.

\section{PATIENTS AND METHODS}

This was a retrospective study, performed at a 650bed university hospital that serves a population of 150,000 inhabitants in Crete, Greece. We reviewed the records of all patients who had positive cultures for $P$. multocida between 1993 and 2004.

Demographic, epidemiological and clinical data including age, sex, animal exposure, site of infection, underlying diseases, type of therapy and outcome were evaluated. All isolates were identified by standard conventional microbiological methods (cell morphology, cultural characteristics, colony morphology, biochemical tests) and by using the API 20NE system (bioMérieux, Marcy L' Etoile, France) ${ }^{[9]}$.
Antibiotic susceptibility testing was performed by the disk diffusion method onto Muller-Hinton agar supplemented with 5\% sheep blood ${ }^{[10]}$ and the MICs of fourteen antibiotics were determined by the E-test method according to the manufacturers' guidelines (Solna, Sweden).

\section{RESULTS}

Patients: Over the 12-year period of the study, 13 cases of $P$. multocida infection were diagnosed at our center. The data of the patients are summarized in Table 1. The male to female ratio was 10:3. With the exception of a 3.5 years old boy, all patients were adults. The mean age was 64.4 years (range $3.5-79$ years) and $8(62 \%)$ of the patients were older than 70 years.

Respiratory tract was the most common site of infection (5 cases with pneumonia, 3 with tracheobronchitis). Septicemia secondary to severe pneumonia and septicemia without any other primary infection was detected in two and one patient, respectively. Cellulitis was diagnosed in three patients. Two of them were scrached by cats, the first on the left leg and the second on the right forearm. The third one was presented with a $P$. multocida wound infection after an injury. The last patient, a 64-year-old woman who had lost her own teeth and substituted them with a denture, presented with an inflammation in the left mandibula on the gingiva with purulent exudate.

Corresponding Author: Dr. Sofia Maraki, Department of Clinical Bacteriology, Parasitology, Zoonoses and Geographical Medicine, University Hospital of Heraklion, P.O. Box 1352, Heraklion 71 110, Crete, Greece, Tel.: +30. 2810.392598, Fax: +30. 2810.392597 
Am. J. Infectious Dis. 1 (2):107-110, 2005

Table 1: Pasteurella multocida infections diagnosed between 1993 and 2004

\begin{tabular}{|c|c|c|c|c|c|c|c|c|}
\hline Case no. & Sex & Age & Animal Exposure & Site of isolation & Infection & Underlying disease & Treatment & Outcome \\
\hline 1 & $\mathrm{M}$ & 55 & Cat scratch & Right forearm & Wound & CBLL & $\begin{array}{l}\text { Amoxicillin/ } \\
\text { clavulanic acid }\end{array}$ & Recovered \\
\hline 2 & M & 78 & Cat scratch & Blood & Septicemia & None & $\begin{array}{l}\text { Ceftriaxone + } \\
\text { netilmicin }\end{array}$ & Recovered \\
\hline 3 & $\mathrm{~F}$ & 77 & Unknown & Blood + BAL & $\begin{array}{l}\text { Pneumonia, } \\
\text { septicemia }\end{array}$ & $\begin{array}{l}\text { Mitral valve } \\
\text { stenosis }\end{array}$ & $\begin{array}{l}\text { Cefuroxime+ } \\
\text { netilmicin }\end{array}$ & Died \\
\hline 4 & M & 79 & Cat and dog & BAL & Pneumonia & $\begin{array}{l}\text { Bowel Ca, } \\
\text { Bullous Pemphigoid }\end{array}$ & $\begin{array}{l}\text { Piperacillin/tazobactam } \\
\text { + Pefloxacin }\end{array}$ & m Died \\
\hline 5 & F & 64 & None(village) & Left mandible & Soft tissues & None & $\begin{array}{l}\text { Amoxicillin }+ \\
\text { metronidazole }\end{array}$ & Recovered \\
\hline 6 & $\mathrm{~F}$ & 48 & Cat scratch & Left leg & Wound & None & $\begin{array}{l}\text { Amoxicillin/ } \\
\text { clavulanic acid }\end{array}$ & Recovered \\
\hline 7 & M & 72 & None(village) & BAL & Pneumonia & $\begin{array}{l}\text { Injured during } \\
\text { agricultural work }\end{array}$ & Ceftriaxone & Recovered \\
\hline 8 & M & 76 & None(village) & Sputum & Tracheobronhitis & Coronary disease & $\begin{array}{l}\text { Amoxicillin/ } \\
\text { clavulanic acid }\end{array}$ & Recovered \\
\hline 9 & M & 75 & Dog & Blood & $\begin{array}{l}\text { Pneumonia, } \\
\text { septicemia }\end{array}$ & Larynx Ca & $\begin{array}{l}\text { Ceftazidime+ } \\
\text { netilmicin }\end{array}$ & Recovered \\
\hline 10 & M & 78 & None(village) & Sputum & Tracheobronhitis & COPD & $\begin{array}{l}\text { Amoxicillin/ } \\
\text { clavulanic acid }\end{array}$ & Recovered \\
\hline 11 & M & 72 & None & Sputum & Tracheobronhitis & $\begin{array}{l}\text { Prostatic } \mathrm{Ca} \text {, } \\
\text { Bone and lung metastasis }\end{array}$ & Cefuroxime & $\begin{array}{l}\text { Recovered } \\
\text { from infection }\end{array}$ \\
\hline 12 & M & 60 & Unknown (village) & BAL & Pneumonia & $\begin{array}{l}\text { Intracranial hemorrhage, } \\
\text { craniotomy }\end{array}$ & Meropenem & $\begin{array}{l}\text { Died from his } \\
\text { main disease }\end{array}$ \\
\hline 13 & M & 3.5 & None (village) & Forehead & Wound & Injury & $\begin{array}{l}\text { Cefotaxime+ } \\
\text { metronidazole }\end{array}$ & Recovered \\
\hline
\end{tabular}

P. multocida was isolated from the bronchoalveolar lavage (BAL) in 3 patients with severe pneumonia, from sputum in 3 patients with tracheobronchitis, from pus in 4 patients with local infections, from blood in 2 patients (one with pneumonia and the other with septicemia without any local infection) and from both blood and BAL in one patient with severe fatal pneumonia.

Underlying disease serving as predisponding factor for the development of $P$. multocida infection was present in 8 patients. Among them, 4 presented a kind of malignancy. Two patients suffered from solid tumors, one from chronic b-lymphocytic leukemia and another one had a history of bowel cancer successfully treated 9 years ago and a recent diagnosis of a bullous pemphigoid under treatment. Mitral valve stenosis, coronary disease, chronic obstructive pulmonary disease and intracranial hemorrhage with a craniotomy and celiostomy were the underlying diseases for the other 4 patients, respectively.

Treatment was successful in 10 cases. Among the three other patients with fatal outcome, a 77-year-old woman was admitted with severe pneumonia, developed ARDS and died within 20 hours, a 79-yearold man with a history of bullous pemphigoid was admitted with pneumonia and ARDS, was treated in the intensive care unit (ICU) where P. multocida was isolated from broncho-alveolar lavage in a concentration up to $10^{9} \mathrm{cfu} / \mathrm{ml}$ and despite the appropriate therapy he died on the $11^{\text {th }}$ day of multiple organ dysfunction syndrome and the third one was a 60 -year-old man who was admitted with intracranial hemorrhage, underwent a craniotomy and celiostomy, was treated in the ICU where developed a $P$. multocida pneumonia on the $10^{\text {th }}$ day and died after 7 days of his main disease. A period longer than 3 years separated these 3 fatal cases.
Regarding the animal exposure, only two of the patients developed the typical form of $P$. multocida soft tissue infection after cat scraches: a 48-year-old woman and a 55-year-old man admitted with cellulitis, developed purulent discharge on the left leg and the right forearm, respectively. Cat scratch was also the portal of entry for a 78-year-old man who was admitted with fever without any local infection and $P$. multocida was isolated from the blood. A retrospective epidemiological history revealed that he had three cats and two dogs at home and he had been scratched by one of his cats on his right forearm, one month ago. After local treatment the lesion healed completely and no signs of soft-tissue infection were present when the bacteremia appeared. A 72-year-old man with pneumonia had injured his left hand during agricultural work a month ago, but he denied any animal exposure. Two patients, one admitted with pneumonia and the other with pneumonia and septicemia owned a cat and a dog the first and a cat the second, but they did not reported bites or scraches. No epidemiological data were available for two fatal cases because of their crucial situation. The other 5 denied any known animal exposure although 4 of them lived in villages.

Bacteriology: All P. multocida isolates were similar in morphology, growth conditions, biochemical profile and antibiotic susceptibility. They were non-motile, gram-negative coccobacilli, well grown on blood and chocolate agar but not onto MacConkey agar. Colonies on blood agar were grey and nonhemolytic with a distinctive mousey odor. They were catalase and oxidase positive and the API 20NE system identified them as $P$. multocida. They fermented glucose, xylose, mannitol and sucrose and presented a similar antibiotic susceptibility profile. They were susceptible to betalactams (amoxicillin, amoxicillin/clavulanic acid, 
cefepime, cefuroxime, ceftriaxone, imipenem and meropenem), quinolones (ciprofloxacin, norfloxacin, levofloxacin and sparfloxacin), chloramphenicol, tetracycline, trimethoprime/sulfamethoxazole. Betalactamase production using nitrocephin disks was negative in all thirteen isolates. Minimal inhibitory concentations (MICs) of the antibiotics tested are given in Table 2.

Table 2: MICs of antibiotics against 13 human isolates of P. multocida

\begin{tabular}{lll}
\hline Antibiotic & $\begin{array}{l}\text { MIC range } \\
(\mu \mathrm{g} / \mathrm{ml})\end{array}$ & $\begin{array}{l}\text { Sucseptible } \\
\text { no }(\%)\end{array}$ \\
\hline Amoxicillin & $0.125-0.75$ & 100 \\
Amoxicillin/clanulanic acid & $0.125-0.75$ & 100 \\
Cefuroxime & $0.023-0.094$ & 100 \\
Cefepime & $0.012-0.125$ & 100 \\
Ceftriaxone & $<0.016$ & 100 \\
Imipenem & $0.125-2$ & 100 \\
Meropenem & $0.016-0.125$ & 100 \\
Ciprofloxacin & $0.008-0.032$ & 100 \\
Norfloxacin & $0.047-0.125$ & 100 \\
Sparfloxacin & $0.003-0.012$ & 100 \\
Levofloxacin & $0.008-0.032$ & 100 \\
Chloramphenicol & $0.38-0.75$ & 100 \\
Trimethoprim/sulfamethoxazole & $0.008-0.125$ & 100 \\
Tetracycline & $0.125-0.5$ & 100 \\
\hline
\end{tabular}

\section{DISCUSSION}

P. multocida infections in humans are well known as animal derived infections (zoonoses), as this organism is a commensal in mouth, throats, noses and gastrointestinal tract of many domestic or wild animals and birds ${ }^{[1]}$. Cats and dogs have the highest carriage rates at $70-90 \%$ and $20-50 \%$, respectively ${ }^{[11]}$. This organism is distributed worldwide and is pathogenic in many animal species, causing serious epizootic infections. Human $P$. multocida infections occur most commonly after animal bites and scratches ${ }^{[2,3]}$. However, several cases have been reported in patients who denied any animal contact. Even without an obvious animal exposure, it is believed that animal secretions are the major source of human infections ${ }^{[12]}$.

Localized infection, secondary to a bite or scratch from an animal, is probably the best-known form of human infection. In our study, only two patients developed this typical form. Respiratory tract is the most common site in $P$. multocida infections unrelated to traumatic animal contact ${ }^{[12]}$. As the majority of our patients were not associated with animal trauma, respiratory tract was unsurprisingly the most common site of the infection (trancheobronchitis, 3; pneumonia, $5)$. Unusual sites such as endocarditis in native or prosthetic valves ${ }^{[5,13]}$, tonsillitis ${ }^{[14]}$, periocular abscess ${ }^{[15]}$ and utero infection in pregnancy ${ }^{[16]}$ have also been reported. There was also a case with an unexpected site of infection among our patients: the patient no. 5 who presented with soft tissue infection with purulent discharge, localized on the gingiva of the left mandible.

It is of interest the preference of this microbe to the extreme ages ${ }^{[6]}$. With the exception of a child, the majority of our patients (8/13) were older than 70 years.

Serious systemic $P$. multocida infections may develop with the presence of different underlying diseases. Rheumatoid arthritis is associated with the development of septic arthritis ${ }^{[4,17]}$, liver dysfunction with septicemia or peritonitis ${ }^{[4,8,18]}$, craniofacial operations with meningitis or intracranial abscesses ${ }^{[6,19]}$, peritoneal dialysis with peritonitis ${ }^{[20,21]}$ and chronic respiratory disease such as bronchitis, emphysema, or bronchiectasis may underlie in respiratory tract infections ${ }^{[4,12,22]}$. Diabetes mellitus ${ }^{[4,23,24]}$, systemic lupus erythematosus ${ }^{[17,25]}$, solid tumors and hematological malignancies ${ }^{[7,23,26]}$ have also been described as underlying diseases in human $P$. multocida infections. Although $P$. multocida bacteremia is strongly associated with liver dysfunction none of our 3 bacteremic patients suffered of any liver disease. One among them suffered from larynx $\mathrm{Ca}$ that is considered a predisposing factor for the infection. A kind of malignancy was also present in other 3 patients.

Although susceptibility of human $P$. multocida isolates to beta-lactams is almost universal ${ }^{[27]}$, betalactamase production by some isolates has been reported and thus susceptibility testing should always be performed $^{[28,29]}$. Susceptibility to tetracycline, chloramphenicol and ciprofloxacin has been demonstrated, while inconsistent clinical results may be found with aminoglycosides, erythromycin, clindamycin and vancomycin ${ }^{[4,19]}$. The results of the antibiotic susceptibility testing of our isolates demonstrated excellent in vitro susceptibility to betalactams, chloramphenicol, trimethoptim/ sulfamethoxazole, quinolones and tetracycline.

Despite the susceptibility and the appropriate therapy, three of the patients died. Outcome is associated with the severity of the infection, the extent of the underlying disease and the early onset of the appropriate therapy ${ }^{[4,26]}$. Mortality is found to be $30 \%$ in meningitis and increased mortality with increasing age has been observed ${ }^{[19]}$. A mortality rate of $31 \%$ is reported in patients with bacteremia, with all fatalities occurring in patients with severe cirrhosis ${ }^{[26]}$. Among our patients with fatal outcome, patient no. 3 died within 24 hours and the other two after prolonged treatment in the ICU.

Pasteurella multocida must be considered as the possible etiology for a variety of infections, especially in patients reporting a history of animal exposure. Early and correct clinical and microbiological diagnosis will lead to the institution of the appropriate antibiotic treatment. 


\section{REFERENCES}

1. Zurlo, J.J., 2000. Pasteurella species. In: Principles and Practice of Infectious Diseases (Eds. G.L. Mandell, J.E. Bennett and R. Dolin) pp: 24022406. Churchill Livingstone, Philadelphia.

2. Francis, D.P., M.A. Holmes and G. Brandon, 1975. Pasteurella multocida infections after domestic animal bites and scratches. JAMA, 233: 42-45.

3. Hubbert, W.T. and M.N. Rosen, 1970. I. Pasteurella multocida infection due to animal bite. Am. J. Public Health, 60: 1103-1108.

4. Weber D.J., J.S. Wolfson, M.N. Swartz and D.C. Hooper, 1984. Pasteurella multocida infections: report of 34 cases and review of the literature. Medicine (Baltimore), 63: 133-154.

5. Elsaghier, A.A.F., CC. Kibbler and J.M.T. Hamilton-Miller, 1998. Pasteurella multocida as an infectious cause of endocarditis. Clin. Infect. Dis., 27: 410.

6. Green, B.T., K.M. Ramsey and P.E. Nolan, 2002. Pasteurella multocida meningitis: Case report and review of the last 11 y. Scand. J. Infect. Dis., 34: 213-217.

7. Grehn, M., F. Muller, A. Hany and P. Meier, 1984. Pasteurella multocida septicemia not associated with primary liver disease. Eur. J. Clin. Microbiol. Infect. Dis., 3: 258-260.

8. Koch, C.A., C.L. Mabee, J.A. Robyn, S.L. Koletar and E.N. Metz, 1996. Exposure to domestic cats: risk factor for Pasteurella multocida peritonitis in liver cirrhosis? Am. J. Gastroenterol., 91: 14471449.

9. Holmes, B., M.J. Pickett and D.G. Hollis, 1999. Pasteurella. In: Manual of Clinical Microbiology (Eds. P.R. Murray, E.J. Baron, M.A. Pfaller, F.C. Tenover and R.H. Yolken) pp: 632-637. ASM Press, Washington DC.

10. Citron, D.M., Y.A. Warren, H.T. Fernandez, M.A. Goldstein, K.L. Tyrrell and E.J.C. Goldstein, 2005. Broth microdilution and disk diffusion tests for susceptibility testing of Pasteurella species isolated from human clinical specimens. J. Clin. Microbiol., 43: 2485-2488.

11. Owen, C.R., E.O. Buker, J.F. Bell and W.L. Jellison, 1968. Pasteurella multocida in animal mouth. Rocky Mt. Med. J., 65: 239-245.

12. Hubbert, W.T. and M.N. Rosen, 1970. II. Pasteurella multocida infection in man unrelated to animal bites. Am. J. Publ. Health, 60: 1109-1117.

13. Nettles, R.E. and D.J. Sexton, 1997. Pasteurella multocida prosthetic valve endocarditis: case report and review. Clin. Infect. Dis., 25: 920-921.

14. Ramdeen, G.D., R.J. Smith, E.A. Smith and L.M. Baddour, 1995. Pasteurella multocida tonsillitis: case report and review. Clin. Infect. Dis., 20: 1055-1057.
15. Hutcheson, K.A. and M. Magbalon, 1999. Periocular abscess and cellulitis from Pasteurella multocida in a healthy child. Am. J. Ophthalmol., 128: 514-515.

16. Waldor, M., D. Roberts and P. Kazanjian, 1992. In utero infection due to Pasteurella multocida in the first trimester of pregnancy: Case report and review. Clin. Infect. Dis., 14: 497-500.

17. Furie, R.A., R.P. Cohen, B.J. Hartman and R.B. Roberts, 1980. Pasteurella multocida infection. Report in urban setting and review of human disease. NY State J. Med., 80: 1597-1602.

18. Tseng, H.K., S.C. Su, C.P. Liu and C.M. Lec, 2001. Pasteurella multocida bacteremia due to non-bite animal exposure in cirrhotic patients: report of two cases. J. Microbiol. Immunol. Infect., 34: 293-296.

19. Kumar, A., H.R. Devlin and H. Vellend, 1990. Pasteurella multocida meningitis in an adult: case report and review. Rev. Infect. Dis., 12: 440-448.

20. London, R.D. and E.J. Bottone, 1991. Pasteurella multocida: zoonotic cause of peritonitis in a patient undergoing peritoneal dialysis. Am. J. Med., 91: 202-204.

21. Mucio, F. and A. Tiu, 1998. Pasteurella multocida peritonitis in peritoneal dialysis. Clin. Nephrol., 49: 258-261.

22. Klein, N.C. and B.A. Cunha, 1997. Pasteurella multocida pneumonia. Semin. Respir. Infect., 12: 54-56.

23. Baker, G.L., C.V. Oddis and T.H. Medsger, 1987. Pasteurella multocida polyarticular septic arthritis. J. Rheumatol., 14: 355-357.

24. Steyer, B.J. and R.E. Sobonya, 1984. Pasteurella multocida lung abscess. Arch. Intern. Med., 144: 1081-1082.

25. Caldeira, L., L. Dutschman, G. Carmo, J. Abreu and G. Sousa, 1993. Fatal Pasteurella multocida infection in a systemic lupus erythematosus patient. Infection, 21: 254.

26. Raffi, F., J. Barrier, D. Baron, H.B. Drugeon, F. Nicolas and A.I. Courtieu, 1987. Pasteurella multocida bacteremia: report of thirteen cases over twelve year and review of the literature. Scand. J. Infect. Dis., 19: 385-393.

27. Mortensen, J.E., O. Giger and G. Rodgers, 1998. In vitro activity of oral antimicrobial agents against clinical isolates of Pasteurella multocida. Diagn. Microbiol. Infect. Dis., 30: 99-102.

28. Rosenau, A., A. Labigne, F. Escande, P. Courcoux and A. Philippon, 1991. Plasmid- mediated ROB-1 $\beta$-lactamase in Pasteurella multocida from human specimen. Antimicrob. Agents Chemother., 35: 2419-2422.

29. Lion, C., A. Lozniewski, V. Rosner and M. Weber, 1999. Lung abscess due to $\beta$-lactamase-producing Pasteurella multocida. Clin. Infect. Dis., 29: 13451346. 